\title{
Variability in the Clearance of Lead Oxide Nanoparticles is Associated with
}

\section{Alteration of Specific Membrane Transporters}

Jana Dumková $\ddagger$, Tereza Smutná ${ }^{1,2}$, Lucie Vrlíková2, Hana Kotasovál, Bohumil Dočekal ${ }^{3}$ Lukáš Čapka ${ }^{3}$, Michaela Tvrdoňová4, Veronika Jakešová2, Vendula

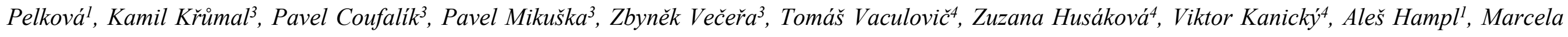
Buchtová ${ }^{2,5}$

${ }^{1}$ Department of Histology and Embryology, Faculty of Medicine, Masaryk University, Brno 625 00, Czech Republic

${ }^{2}$ Laboratory of Molecular Morphogenesis, Institute of Animal Physiology and Genetics, v.v.i., Czech Academy of Sciences, Brno 602 00, Czech Republic

${ }^{3}$ Institute of Analytical Chemistry, v.v.i., Czech Academy of Sciences, Brno 602 00, Czech Republic

${ }^{4}$ Department of Chemistry, Faculty of Science, Masaryk University, Brno 625 00, Czech Republic

${ }^{5}$ Section of Animal Physiology and Immunology, Department of Experimental Biology, Faculty of Science, Masaryk University, Brno 625 00, Czech Republic $\ddagger$ Authors contributed equally 
Table S1. Histopathological changes in the lungs after 6 and 11 weeks of PbO NPs inhalation

\begin{tabular}{|c|c|c|c|c|c|c|c|c|c|c|c|c|c|c|c|c|c|c|c|c|c|c|c|c|c|}
\hline \multirow{2}{*}{ lung } & \multicolumn{5}{|c|}{ ctr $/ 6 w$} & \multicolumn{5}{|c|}{$\mathrm{PbO} / 6 \mathrm{w}$} & \multicolumn{5}{|c|}{ ctr/11w } & \multicolumn{5}{|c|}{$\mathrm{PbO} / 11 \mathrm{w}$} & \multicolumn{5}{|c|}{$\mathrm{PbO} / \mathrm{cl}$} \\
\hline & col & $\operatorname{co} 2$ & $\operatorname{co3}$ & $\operatorname{co} 4$ & $\operatorname{co5}$ & $\mathrm{Pb} 1$ & $\mathrm{~Pb} 2$ & $\mathrm{~Pb} 3$ & $\mathrm{~Pb} 4$ & $\mathrm{~Pb} 5$ & col & $\operatorname{co} 2$ & \begin{tabular}{|l|}
$\operatorname{co} 3$ \\
\end{tabular} & $\operatorname{co} 4$ & $\cos$ & $\mathrm{Pb} 1$ & $\mathrm{~Pb} 2$ & $\mathrm{~Pb} 3$ & $\mathrm{~Pb} 4$ & $\mathrm{~Pb} 5$ & $\mathrm{cll}$ & $\mathrm{cl} 2$ & $\mathrm{cl} 3$ & $\mathrm{cl} 4$ & $\mathrm{cl5}$ \\
\hline infiltrate peribron. & & & & & & & & & & + & & + & + & + & + & & + & + & & ++ & & & & & \\
\hline infiltrate perivasc. & & & & & & & & & & + & & & & & & & + & & & & + & & + & & \\
\hline atelectasis & & & & & & & & & & & & & & & & + & & & & & & & & & \\
\hline bronchiolitis & & + & + & + & ++ & + & & & & ++ & + & & & & & + & + & & & & & & & & \\
\hline thickened septa & & & + & ++ & ++ & ++ & ++ & ++ & + & + & + & ++ & + & + & + & ++ & + & ++ & ++ & + & ++ & + & + & + & + \\
\hline alveolar emphysema & & & & & & & & + & & & & & + & & & ++ & & + & + & & & + & & & \\
\hline foamy macrophages & & & & & & & & & & & & & & & & & & + & + & + & & & & & \\
\hline hemorrhage & & & & & & & & & & & & & & & + & + & & & & & & + & & + & \\
\hline
\end{tabular}

We evaluated at least 8-10 slides per organ and assessed alterations in histopathological changes as follows: peribronchiolar infiltrate, perivascular infiltrate, atelectasis, bronchiolitis, thickened alveolar septa, presence of foamy macrophages in lung, and hemorrhage. Increased level of phenotype was labelled by increased number of + symbols, where "+" means mild phenotype, "++" moderate phenotype, and "+++" serious phenotype (no present) in relevant type of alteration in given organ;

co1 - co5 control animals, Pb1 - Pb5 PbO NPs exposed animals, cl1 - cl5 animals after clearance period. 
Table S2. Histopathological changes in the liver after 6 and 11 weeks of PbO NPs inhalation

\begin{tabular}{|c|c|c|c|c|c|c|c|c|c|c|c|c|c|c|c|c|c|c|c|c|c|c|c|c|c|}
\hline \multirow{2}{*}{ liver } & \multicolumn{5}{|c|}{ ctr/6w } & \multicolumn{5}{|c|}{$\mathrm{PbO} / 6 \mathrm{w}$} & \multicolumn{5}{|c|}{ ctr/11w } & \multicolumn{5}{|c|}{$\mathrm{PbO} / 11 \mathrm{w}$} & \multicolumn{5}{|c|}{$\mathrm{PbO} / \mathrm{cl}$} \\
\hline & col & $\operatorname{co} 2$ & $\operatorname{co} 3$ & $\operatorname{co} 4$ & $\operatorname{co5}$ & $\mathrm{Pb} 1$ & $\mathrm{~Pb} 2$ & $\mathrm{~Pb} 3$ & $\mathrm{~Pb} 4$ & $\mathrm{~Pb} 5$ & col & co2 & co3 & $\operatorname{co} 4$ & $\operatorname{co5}$ & $\mathrm{Pb} 1$ & $\mathrm{~Pb} 2$ & $\mathrm{~Pb} 3$ & $\mathrm{~Pb} 4$ & $\mathrm{~Pb} 5$ & $\mathrm{cll}$ & $\mathrm{cl} 2$ & $\mathrm{cl} 3$ & $\mathrm{cl} 4$ & $\mathrm{cl} 5$ \\
\hline MN cell infiltrate & + & + & + & & & + & + & + & & ++ & & + & + & + & + & + & + & + & + & + & + & & + & + & + \\
\hline focal necrosis & & & & & & & + & & & + & & & & & & + & & & & & + & & & & \\
\hline polynuclear hep. & & & & & & & & & & & & & & & & & & + & & & & & & & \\
\hline steatosis macroves. & & & & & & & & & & & & & & & & & & & & & & & & & \\
\hline hemostase & & + & + & + & & + & & ++ & & + & + & + & + & & & ++ & + & + & + & ++ & + & + & & + & ++ \\
\hline hepatic remodeling & & & & & & & & + & & + & & & + & & & + & & + & + & ++ & ++ & & & & + \\
\hline hypertrophic hep. & & & & & & & & & & + & + & & ++ & & & & & + & ++ & & + & & + & + & + \\
\hline inf. in portal area & & & & & & & & & & & + & & & & & & & & + & & + & + & & & \\
\hline
\end{tabular}

We evaluated at least 8-10 slides per organ and assessed alterations in histopathological changes as follows: mononuclear (MN) cell infiltrate, focal necrosis (degenerating hepatocytes), polynuclear hepatocytes, macrovesicular steatosis, hemostase, hepatic remodeling, hypertrophic hepatocytes, and infiltrate in portal area. Increased level of phenotype was labelled by increased number of + symbols, where "+" means mild phenotype, "++" moderate phenotype, and "+++" serious phenotype (no present) in relevant type of alteration in given organ;

co1 - co5 control animals, Pb1 - Pb5 PbO NPs exposed animals, cl1 - cl5 animals after clearance period. 
Table S3. List of antibodies used for immunohistochemical analysis

\begin{tabular}{|c|c|c|c|c|c|c|c|}
\hline Primary antibody & Company & Catalog no. & Host species & Organs & Pre-treatment (citrate buffer) & Dilution & Time/temperature \\
\hline PCNA & $\begin{array}{c}\text { Dako } \\
\text { Cytomation }\end{array}$ & M0879 & mouse & lung, liver & $\begin{array}{l}15 \mathrm{~min} / 97^{\circ} \mathrm{C} \text { (lung) } \\
20 \mathrm{~min} / 97^{\circ} \mathrm{C} \text { (liver) }\end{array}$ & $1: 50$ & $60 \mathrm{~min} / \mathrm{RT}$ \\
\hline SOX2 & Cell Signaling & $2748 S$ & rabbit & lung & $25 \mathrm{~min} / 97^{\circ} \mathrm{C}$ & $1: 200$ & overnight $/ 4^{\circ} \mathrm{C}$ \\
\hline CD68 & Abcam & $A b 125212$ & rabbit & lung, liver & $\begin{array}{l}15 \mathrm{~min} / 97^{\circ} \mathrm{C} \text { (lung) } \\
20 \mathrm{~min} / 97^{\circ} \mathrm{C} \text { (liver) }\end{array}$ & $1: 100$ & $60 \mathrm{~min} / \mathrm{RT}$ \\
\hline
\end{tabular}


Table S4. List of antibodies used for indirect immunofluorescence

\begin{tabular}{|c|c|c|c|c|c|c|c|}
\hline Primary antibody & Company & Catalog no. & Host species & Organs & Pre-treatment (citrate buffer) & Dilution & Time/temperature \\
\hline SOX9 & Sigma-Aldrich & $H P A 001758$ & rabbit & liver & $20 \mathrm{~min} / 97^{\circ} \mathrm{C}$ & $1: 100$ & overnight $/ 4^{\circ} \mathrm{C}$ \\
\hline $\mathrm{Na}^{+} / \mathrm{K}^{+}$- ATPase & Abcam & EP1845Y & rabbit & lung, liver & $25 \mathrm{~min} / 97^{\circ} \mathrm{C}$ & $1: 80$ & $60 \mathrm{~min} / \mathrm{RT}$ \\
\hline
\end{tabular}


Table S5. Primers for qPCR

\begin{tabular}{|c|c|c|}
\hline Gene & Oligonucleotide (primer) & Annealing temperature \\
\hline Abcc3 & F 5' TTTGTGCAGCGCTTCTATGTG 3' & $59^{\circ} \mathrm{C}$ \\
\hline & R 5' ATGACACTGGTGCCCGTTAC 3' & \\
\hline
\end{tabular}




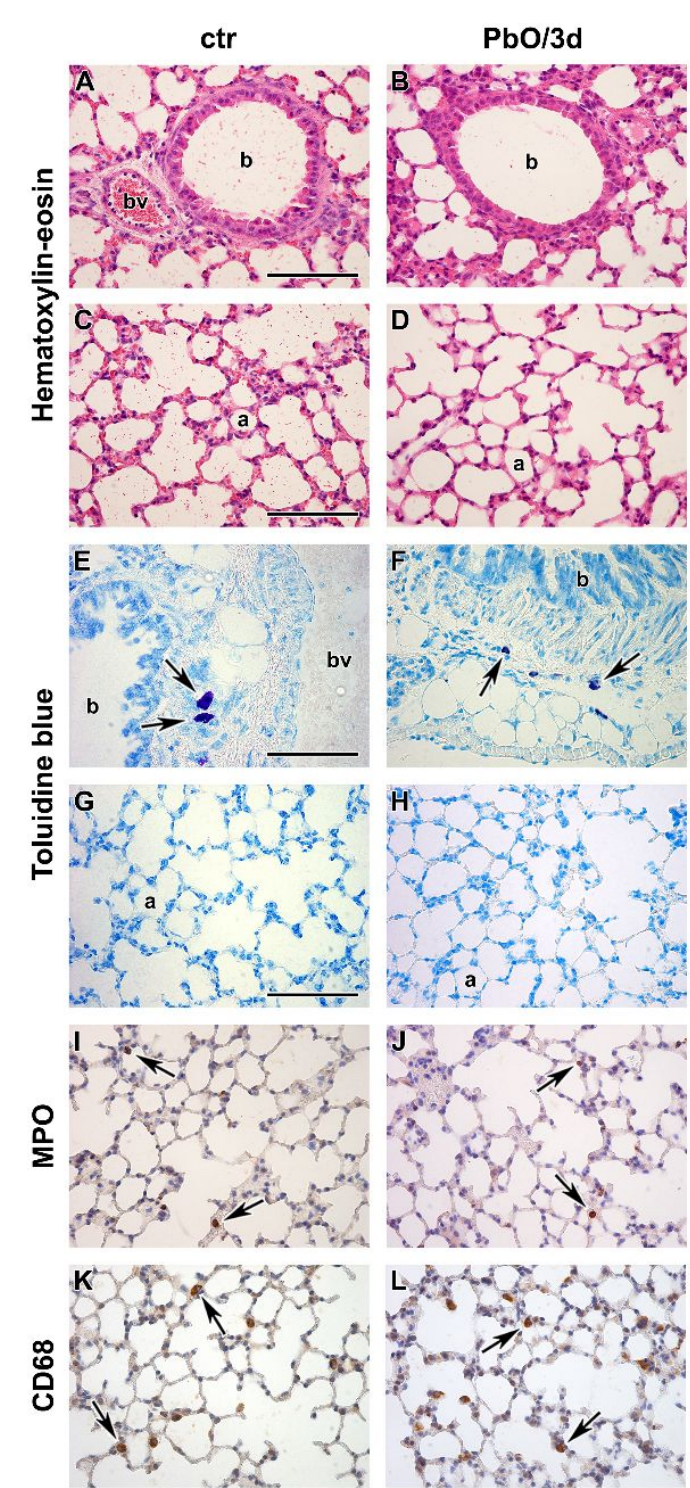

CD68

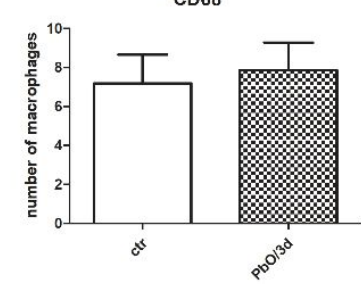

Figure S1. Lung after 3 days of PbONPs inhalation

A, C) Lungs in control animals. B, D) Lung tissue after 3 days of PbONPs inhalation did not reveal any morphological changes both in alveolar areas (a) or in the areas surrounding bronchioles (b). E-H) Toluidine blue staining of mastocytes (arrows). Mastocytes were detected only around large bronchioles (b). In the alveolar areas (a), there was no presence of mastocytes both in control or experimental group. I, J) Immunohistochemical detection of myeloperoxidase uncovered no changes in amount of neutrophils (arrows). K, L) Detection of CD68-positive cells (marker of macrophages) in the lung tissue. The number of macrophages was not altered after 3 days of PbONPs inhalation (arrows). M) Detail evaluation of macrophages numbers did not reveal any significant changes. The graphs values denote average \pm SD.

Scale bar in all panels $=100 \mu \mathrm{m}$. 

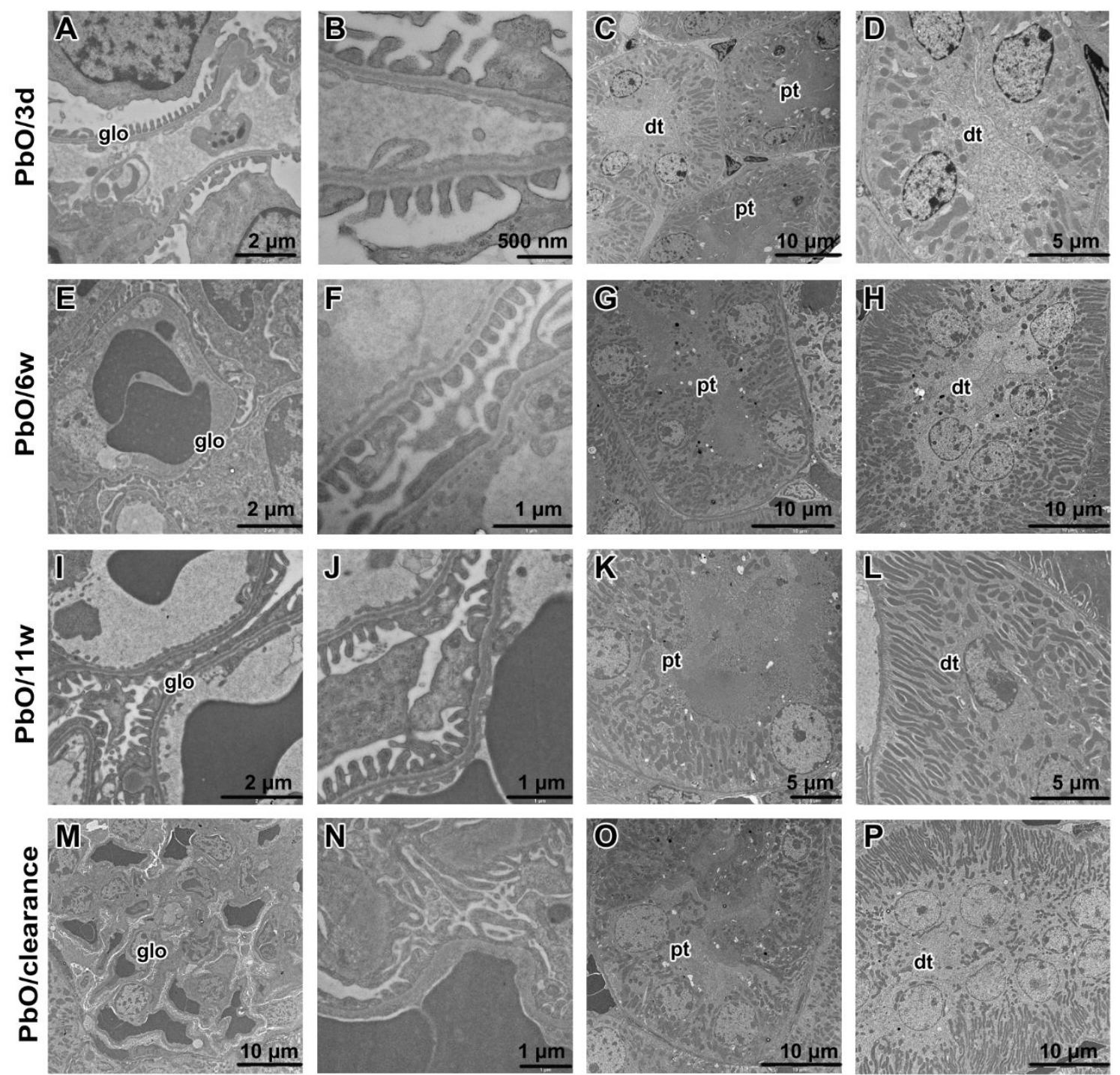

Figure S2. Ultrastructure of kidney after PbO NPs exposure. Both glomerular (glo) and tubular parts (proximal tubules, $p t$, and distal tubules, $d t$ ) of kidney were without pathological changes. 

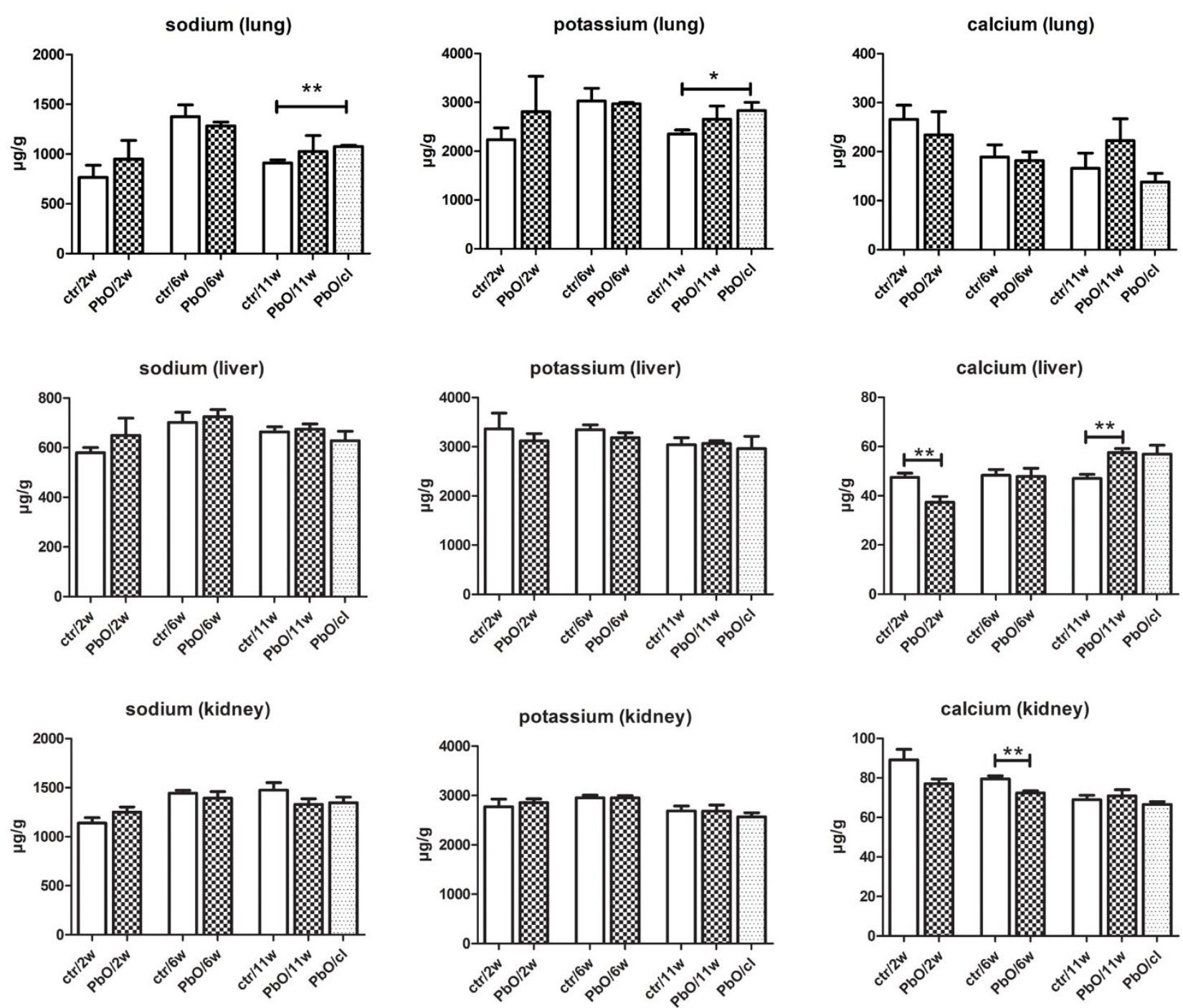

Figure S3. The content of elements (sodium, potassium, and calcium) in lung, liver, and kidney during subchronic PbO NPs inhalation.

The graphs values denote average $\pm \mathrm{SD}, * \mathrm{p}<0.05$ compared with the corresponding control group (ctr), and $* * \mathrm{p}<0.01$ compared with the corresponding control group (ctr). 

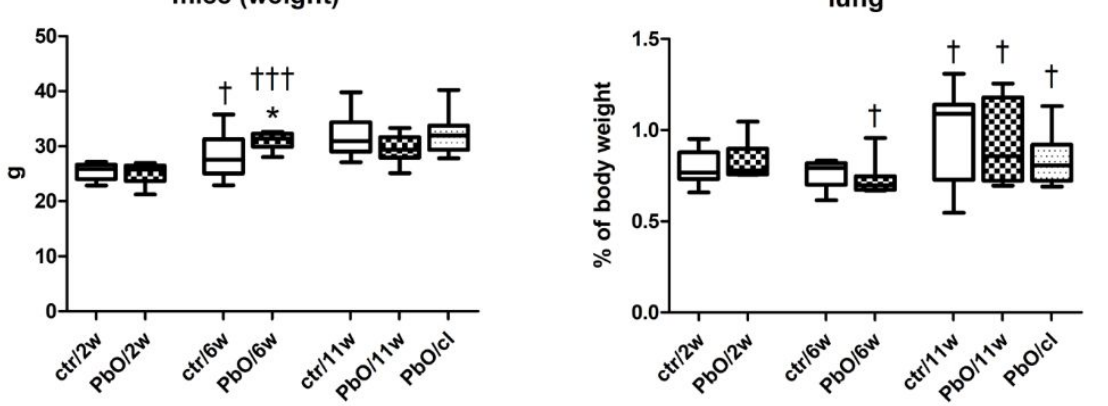

kidney (right)

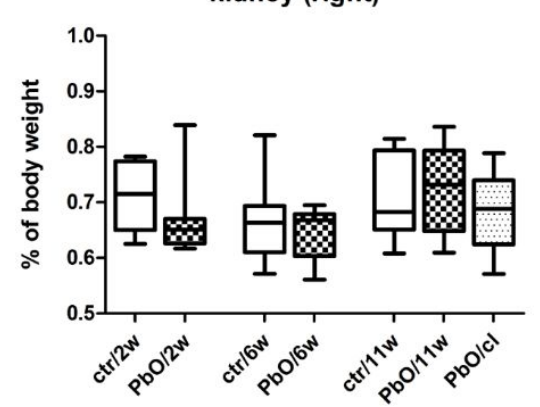

kidney (left)

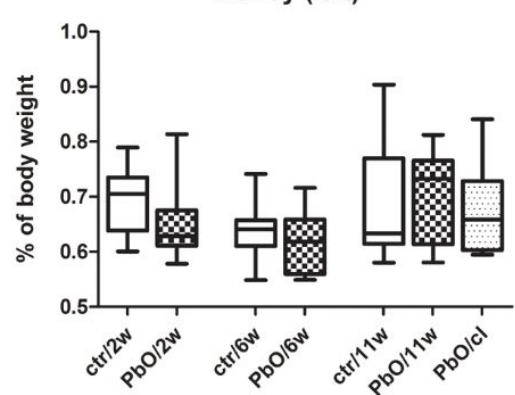

spleen

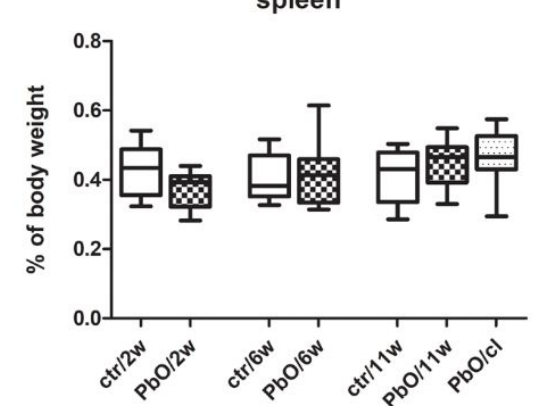

Figure S4. Weight of mice during PbO NPs inhalation. Lung, kidney, and spleen weight coefficient at different time points (2, 6, and 11 weeks). The graphs values denote average $\pm \mathrm{SD}$;

$* \mathrm{p}<0.05$ compared with the corresponding control group (ctr),

$\dagger \mathrm{p}<0.05$ compared with the previous control or PbO NPs group,

$\dagger \dagger \dagger \mathrm{p}<0.001$ compared with the previous control or PbO NPs group. 


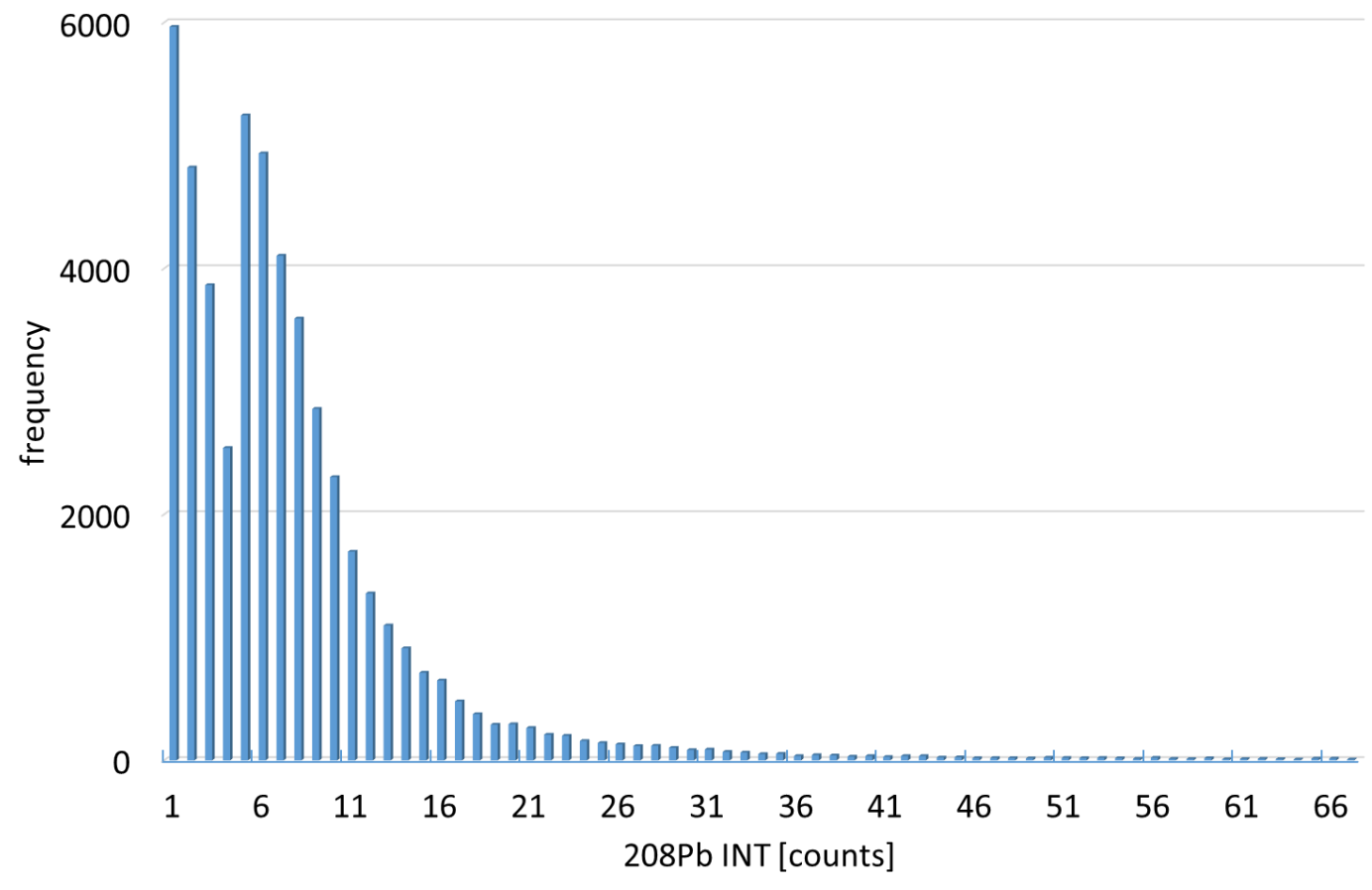

Figure S5. Histogram of intensities of ${ }^{208} \mathrm{~Pb}$ obtained at laser ablation of filter. 